\title{
Ungulani Ba Ka Khosa: literatura e eficácia
}

\author{
ROBSON DUTRA \\ Unigranrio-RJ
}

\begin{abstract}
RESUMO: RESULTADO DE UMA HETEROGENEIDADE QUE CONTA COM A EFETIVA CONTRIBUIÇÃO DE ÁRABES, INDIANOS, PORTUGUESES, ALÉM DE DIVERSAS ETNIAS AFRICANAS, A SOCIEDADE MOÇAMBICANA TEM SIDO REFLETIDA PELA LITERATURA POR DIVERSAS ESTRATÉGIAS QUE TENTAM DAR CONTA DOS DESVÃOS DE SUA HISTÓRIA. ESTE TEXTO TEM COMO BASE O DISCURSO LITERÁRIO DE UNGULANI BA KA KHOSA, QUE ABRE MARGENS AO MULTIPERSPECTIVISMO QUE AMPLIA OS LIMITES ENTRE SOCIEDADE E ARTE, QUESTIONANDO O CONCEITO DE VERDADE, DO PRESENTE E DO PASSADO PARA FAZER DA INTERROGAÇÃO DO OUTRORA UMA NOVA CATEGORIA EPISTEMOLÓGICA.
\end{abstract}

ABSTRACT: RESULTING FROM A HETEROGENEITY THAT HAS EFFECTIVE CONTRIBUTION OF ARABS, INDIANS AND PORTUGUESE, AMONG OTHER AFRICAN ETHNICITIES, MOZAMBICAN SOCIETY HAS BEEN EFFECTIVELY REFLECTED BY LITERATURE THROUGH MULTIPLE STRATEGIES THAT COVER ITS HISTORICAL BACKGROUND. THIS TEXT HAS ITS STARTING POINT ON UNGULANI BA KA KHOSA'S WRITING AND THE MULTIPERSPECTIVISM THAT EXTENDS THE LIMITS BETWEEN SOCIETY AND ART, ALSO INQUIRING THE CONCEPT OF TRUTH, PRESENT AND PAST IN ORDER TO MAKE THE INTERROGATION OF YESTERDAY A NEW EPISTEMOLOGICAL CATEGORY.

PALAVRAS-CHAVE: UNGULANI BA KA KHOSA, LITERATURA MOÇAMBICANA, MULTIPERSPECTIVISMO, SOCIEDADE E ARTE.

KEYWORDS: UNGULANI BA KA KHOSA, MOZAMBICAN LITERATURE, MULTIPERSPECTIVISM, SOCIETY AND ART. 
os heróis que cantaste, que restou senão a melodia do teu canto? As armas em ferrugem se desfazem, os barões nos seus jazigos dizem nada. É teu verso, teu rude e suave balanço de consoantes e vogais, teu ritmo de oceano sofreado que os lembra ainda e sempre lembrará. Tu és a história que narraste, não o simples narrador. Ela persiste mais em teu poema que no tempo neutro, universal sepulcro da memória.

(Carlos Drummond de Andrade)

Ao discorrer sobre Moçambique, Michael Cahen (1995, p. 97) reafirma a multiplicidade cultural que faz com que não haja, neste país, uma identidade banta una. Ao contrário, este autor afirma que esta se divide em consciências múltiplas que se associam às diversas etnias ali presentes, como macuas, macondes, tchopes etc., que se somam, por sua vez, às influências deixadas por árabes, indianos, muçulmanos e portugueses. Tal característica resulta inegavelmente de fatores históricos a que se somam outros de natureza geopolítica, de viés econômico e administrativo, exacerbados, sobretudo, pelo regime colonial, de modo que o Estado moçambicano vem tentando construir aquilo que poderíamos definir como identidade nacional.

Inevitavelmente, toda essa multiplicidade é refletida pela literatura e a crítica literária é unânime em afirmar que, se a produção moçambicana do período pré-colonial ocupou-se, dentre outros, de temas que faziam com que o toque do tambor clamasse pela Independência, a discursividade literária no período pós-colonial se dá por intermédio de duas fases distintas.

A primeira cobre um espaço de quase dez anos e conta com uma produção que alguns desses críticos definem como de predominante exaltação patriótica, visto que é centrada em constantes referências a heróis e fatos que se associam, direta ou indiretamente, ao processo de libertação nacional, numa celebração eufórica do país recém-nascido. A segunda, que se origina em meados dos anos 80, notadamente na "Geração da Charrua", cujo objetivo seria revolver os terrenos da utopia interiorizada, constrói-se, na maioria das vezes, por meio de posições antidoutrinárias e de uma maior heterogeneidade, quer no aproveitamento de temas antes tangenciados, quer no questionamento do verdadeiro estatuto dos heróis de outrora.

É precisamente nesta fase que desponta a escrita literária de Ungulani Ba Ka Khosa, um autor reticente em comentar sua biografia por valer-se da pre- 
missa de Roland Barthes, referenciada na capa de seu livro de contos intitulado Orgia de loucos, para quem "só há biografia enquanto a vida é improdutiva. Desde que produzo, desde que escrevo, é o próprio texto que se apropria (felizmente) do meu tempo narrativo".

Contudo, uma pesquisa tanto em sua obra quanto naquelas ao seu respeito nos faz saber que seu nome, de origem tsonga, é Francisco Esaú Cossa, nascido em Inhaminga, Sofala, às 00h45min de primeiro de Agosto de 1957. Seus pais, de origens sena e changana, foram enfermeiros assimilados, fato que o aproximou, aos 12 anos de idade, da língua portuguesa e da leitura de escritores como Hemingway, Sartre, Dostoievsky e Gogol. Tempos depois, e após viver em diversas localidades de seu país, Khosa dedicou-se à leitura de autores latino-americanos, atraído tanto pelas similaridades histórico-sociais com a África, quanto pela estrutura oral que faz fluir o realismo mágico presente nestes textos (Chabal, p. 310).

Com efeito, um dos traços principais de sua escrita é uma indisfarçada disforia que o incita a esmiuçar as lacunas do tecido da história de Moçambique, apontando para novas representações dos fatos que a constituem. Neste sentido, é indubitavelmente importante a atuação que teve no pósindependência, a partir de 1978, nos campos de reeducação administrados pela FRELIMO, com o intuito de forjar o "homem novo". Vêm dessa época seus primeiros impulsos literários, quando, após presenciar uma série de arbitrariedades, Khosa sentiu

a necessidade realmente de escrever para falar dessa realidade e expor o que muitas pessoas não sabiam. Achava que era importante que isso se soubesse. O contato que eu tive foi com presos de delitos comuns, não políticos. Para mim foi uma realidade nova ver aquilo. Presenciar uma experiência e, por outro lado, os erros que se iam cometendo nessa experiência. Ver a frustração das pessoas. A experiência que pretendia ser de que, passados dois, três anos, as pessoas estivessem reeducadas, mas realmente não estavam (Chabal, p. 310).

Por isso, seus textos põem em cena a noção de que um fato histórico é suscetível de, pelo menos, duas narrações. Essas modalidades discursivas, a histórica e a ficcional, têm como marca a relação de complementaridade resultante 
do fato de seus discursos terem como objetivo comum oferecer uma imagem verbal da realidade (White, p. 20). Se pensarmos ainda que a história busca a legitimação de sua veracidade sem necessariamente se desvincular de seu referente, tampouco impugnar a dicotomia entre verdadeiro e falso, chegaremos ao que Hayden White denomina "operatividade". Como discurso, contudo, calcado na representação de um passado com pretensão a real, Khosa recorre a estratégias textuais que absolutizam seu estado de "instrumento de mediação" e lhe auferem o que se chama "performatividade". Desse modo, os dois discursos possíveis sobre determinada realidade ocorrem simultaneamente, sem necessariamente nenhuma relação de exclusão ou desvinculação.

Esta é, parece-nos, a razão por que a história e as origens míticas de Moçambique se tornaram veículos de afirmação cultural e de reivindicação político-ideológica de que $\mathrm{Ba} \mathrm{Ka}$ Khosa não prescinde em seus textos e aos quais retorna sistematicamente, o que se pode verificar em Orgia de loucos, obra publicada em 1990, por exemplo, em que este autor lança mão de uma linguagem rebuscada e de um tom hiperbólico, para dar conta dos desdobramentos político-sociais ocorridos na Moçambique pós-colonial.

O signo da distopia é antecipado nas duas epígrafes que lhe servem de pórtico. Uma, de Marguerite Yourcenar: "A felicidade é frágil, e quando a não destroem os homens ou as circunstâncias, ameaçam-na os fantasmas"; outra, do poeta moçambicano Jorge Viegas: "No meu país a única forma de liberdade permitida é a loucura". A partir daí dá-se o desdobramento de nove narrativas de forte teor alegórico, em que a guerra e a morte são protagonistas. Dentre elas, destacamos a primeira, "O prêmio", em que a alegria inerente ao nascimento de uma criança cede espaço à decepção da mãe por trazê-la ao mundo cinco minutos antes do raiar de um novo dia, quando ela ganharia a aludida recompensa, um enxoval completo. A enunciação revela ainda que as dores da mãe, metaforizadas no suor excessivo que "como formigas emergindo dos casulos" tomam a dimensão de "grãos de milho esparsos em campos sem dono" (p. 15) se prolongam, infinitamente, após o nascimento do filho, fazendo-a ignorar o bebê e as palavras de apoio da enfermeira - subitamente transformada em feiticeira -, que exaltam a saúde do menino, para render-se à desilusão de um "tempo perdido" (p. 19).

O nascimento é, igualmente, tema do conto subsequente, "A Praga"; neste caso, o de dois meninos em meio a águas revoltas. Os desdobramentos se 
dão quando Luandle, filho de um pescador, vem ao mundo em meio a uma tempestade em alto-mar, residência de espíritos que lançam uma maldição sobre a família, matando a mãe e afastando o pai do mar e do sustento da casa. Após transformarem o oceano em abrigo apenas de "restos de naufrágios do tempo de Vasco da Gama, que vinham à tona sem nenhum esforço" (p. 27), são estes espíritos que fazem com que pai e filho abandonem o litoral rumo ao interior do país, a fim de tentarem reconstruir suas vidas. É ali que se dá o nascimento do filho de Luandle, mais uma vez em meio à enchente caudalosa de um rio que faz com que todos - avô, filho e mãe - se abriguem com os animais no cimo das árvores. Ciente da desgraça que se perpetua, o avô pede ao filho que dê ao neto o nome Kufeni, substantivo que designa a morte, para, em seguida, lançar-se às águas que lhe tragarão a vida. Mesmo assim, a praga se propaga através de uma série de outras perdas, como, mais uma vez, o desaparecimento da mãe, trazendo consigo males que, cada vez, mais suplantam os períodos de paz e de fartura.

O conto "A solidão do Senhor Matias" também retrata a guerra, trazendo à cena o mar em ruínas. Desta vez, contudo, sua interdição se estende ao homem branco a que o título alude, o qual - protagonista de desmandos - vê-se irremediavelmente sentenciado por uma das muitas negras que violou, a não mais singrar os mares, agora plenamente navegados, que o levariam de volta à terra natal. Assim, a personagem deambula por cenários do caos posterior ao 25 de abril, que a levam a cavar seu túmulo ao pé da sepultura da mulher branca, fazendo valer a maldição lançada sobre os antigos colonos.

"Morte inesperada", sexto conto de Orgia dos loucos, revela a árdua coexistência de tradições rurais no meio urbano, expressa pelo entrecruzamento de diversas narrativas, que, mais uma vez, espelham a realidade moçambicana. Dentre elas, a que dá título ao conto, ou seja, a morte macabra de Simbine, que teve a cabeça decepada pelo elevador do prédio em que reside, é atribuída à troca da enxada pelos livros (p. 69), ou seja, à migração do campo para a cidade e à difícil convivência de suas três mulheres e seus muitos filhos neste novo locus, numa clara referência à poligamia existente naquele país (p. 71). À morte segue-se a loucura que acomete o passageiro aprisionado no elevador e que é associada ao consumo desenfreado de cigarros (p. 70). Por último, a embriaguez constante do policial requisitado para investigar o caso, porque jamais poderá desposar uma mulher, resulta do fato de ele, o policial, haver, 
anos antes, insultado em público uma tia-avó, "chamando-a feiticeira" (p. 71).

Todos esses dilemas convergem para a última narrativa da obra, "Fábula do futuro", em que, numa retomada súbita do desejo que o impeliu à escrita, Ungulani Ba Ka Khosa volta-se para o desejo utópico que o faz afirmar que

apesar dos seixos, dos cascalhos, das margens, tentarem raivosamente travar o movimento das águas, elas correm, límpidas, belas e, como mulheres esbeltas, saracoteiam maviosamente as ancas, deixando as margens comidas pela inveja e os seixos desprovidos de ódio.

Adiante, sempre contumazes, os troncos atiram-se às águas tentando desviar o curso construído com suor. Em remoinhos sonoros, vibrantes, as águas transpõem e arrastam consigo os vários obstáculos com sorriso prateado, reluzindo à superfície.

E o mar, sempre aberto, eis que a todos recebe: é o estuário que engolfa, é o delta que se atira desordenadamente, é a escória que se infiltra. E nesse movimento contínuo, perene, nunca se alterou a cor das águas do mar, as suas ondas, a sua coqueluche. É a democracia da natureza. (p. 63).

Em No Reino dos abutres (2002), contudo, o sentimento de distopia volta a se apossar da enunciação e se revela na dedicatória da obra: "aos irmãos que pereceram por ideias nunca esconjuradas" e, mais uma vez, na epígrafe de Milan Kundera: tout sera oublié, rien sera reparé, ou seja, tudo será esquecido, nada reparado.

Parte desta "não reparação" é divida com o leitor, visto que, na introdução, Khosa afirma que este livro deveria chamar-se Ngodo, que, em língua tchope, designa a orquestra de marimbas, dançarinos e seu respectivo coro. A função de solista é, neste caso, dividida entre ele, que se responsabiliza pelo primeiro e décimo capítulos, Mutsitso (Introdução Orquestral) e Nïiriri (Final dos Dançarinos), respectivamente, cabendo ao leitor a condução dos demais "andamentos".

Ao longo do texto, a rica adjetivação faz comparações inequívocas com um passado distante e corroído que se revela em trechos como:

O sol caía. O vento, entrando pelas frestas da palhota grande, foi ocupando a sala com a lentidão dos camaleões sem o mimetismo do medo e do disfarce; e com a leveza dos espíritos nunca vistos, passou o corpo pelo tampo da mesa, estendeu as mãos pelas cadeiras sem pés e braços, atirou os olhos sem 
as íris aos velhos trastes em agonia, roçou com a língua a esteira esburacada, desarrumou os copos e os pratos partidos dos tempos de fartura, descolou as paredes de adobe as fotografias dos ascendentes perdidos no emaranhado indestrinçável das lianas do tempo, espantou as baratas em cio, expulsou o ar amordaçado da sala desde os tempos de vozes ciciadas pelo medo da autocrítica pública - reprimenda que consistia na confissão pública, entre outros males, das modalidades extraconjugais ante o riso e a avidez dos chefes fardados com a balalaica única do partido único que exigiam dos infratores a reconstituição pela fala e pelos gestos do coito que ia do chio da lebre (...) até a lassidão das lombrigas, e embrenhou-se no corredor dos passos desconhecidos, enquanto o ar da memória pulverizava a porta sem dobradiças e contava a todo mundo os segredos por todos conhecidos (p. 5).

Com efeito, a obra tem, entre seus loci enunciativos, a cidade, o meio rural e os campos de reeducação localizados na região do Niassa, do Cabo Delgado e de Sofala, a que foram conduzidos, dentre outros, dissidentes do partido único, tidos, por isso, como "inimigos do povo"; membros de grupos religiosos; os considerados "improdutivos" pelo regime; prostitutas; bem como jovens com curso superior, com o alegado objetivo de desenvolver regiões onde havia pouca população. A obra faz, igualmente, que se entreveja a instalação do aparelho policial e repressivo característico dos regimes socialistas que gerou também desencanto entre a população, sobretudo urbana, em expansão rápida nos anos 70 e 80, e as próprias bases da FRELIMO.

Estas características são alegorizadas em personagens como Tomás, um ancião cujo discurso é constituído quase integralmente por ditados populares que apontam tanto para suas origens simplórias quanto para um saber oralizado que foi, na altura, contestado. Enviado ao Niassa, o ancião ocupa o tempo pintando cruzes nas palhotas dos mortos (p. 18) e cuidando de Armando, um dissidente do exército revolucionário e da Academia Militar, por espontaneamente, revelar vícios pequeno-burgueses (p. 21) e uma opção sexual divergente (p. 22). Todo este aparato repressivo resulta em melancolia, sobretudo a que abate João Guambe, marido de Josefa, que é castrado, sem qualquer motivação política, "por homens armados" (p. 44) que o privam do presente e do futuro, já que com ele se encerra a linhagem de artesãos de sua família. A interdição ao sexo e à procriação aponta, igualmente, para o des- 
povoamento futuro de uma terra, tanto de homens quanto de sonhos, num prolongamento sem fim de um estado de letargia e ensimesmamento.

Como é comum à escrita de $\mathrm{Ba} \mathrm{Ka}$ Khosa, a diegese faz incontáveis associações entre homens e animais, num zoomorfismo degradante que retoma algumas dos princípios estéticos que o Neo-realismo ofereceu aos problemas das classes oprimidas, nos anos 40. Neste romance, a menção constante ao estado de selvageria do homem soa como um brado contra a alienação que grassa numa "terra sonâmbula" regida por abutres. É em seu solo que serpentes, formigas, baratas e outros insetos contemplam, estupefatos, seres humanos bestializados como Armando, descrito como um lagarto pré-histórico que só se aproxima da condição humana quando se droga com a "suruma ou, na falta desta, com merda seca de elefante" (p. 22).

Uma das poucas exceções à inexorabilidade do destino, em No Reino dos abutres, é a linha que o autor estabelece entre os homens e o gado que é batizado com nomes humanos, numa tentativa de retomada de uma ancestralidade que engloba ícones do mundo visível e invisível da sabedoria banto, a qual se mostra, contudo, irremediavelmente perdida em um mar de dejetos humanos.

Uma outra característica da escrita de Khosa é o notável excesso de secreções e líquidos vertidos sistematicamente pelo corpo humano, como suores, saliva, vômitos, lágrimas, urina, fezes e sangramento, num processo de degradação do ser que tateia o insólito e o grotesco com o intuito, parece-nos, de revelar todo um processo de inadaptabilidade e de incapacidade de regeneração do homem e de seu destino. Lemos em Bakhtin que "rebaixar o corpo humano consiste em aproximá-lo da terra” (1996, p.19), numa representação do princípio de absorção, de morte e de semeadura. O corpo inacabado, que se apresenta como resto, e em contínua troca com o mundo é também o corpo rebaixado, o dos excessos, dos orifícios, dos excrementos e do sexo. Essa representação funciona, nos diversos textos, através de hipérboles, como um emblema do realismo que vai do insólito ao grotesco e de sua franca oposição ao modelo clássico de representação do mundo. Nada há de nada estável ou perfeito nesse corpo humano que é, efetivamente, "a quintessência da incompletude" (p. 23), ao anunciar tanto a proximidade da morte quanto, nos textos em questão, uma possibilidade distanciada de recondução àquilo que caracteriza a humanidade. Diferentemente do realismo grotesco bakhtiniano, contudo, em Khosa, parece não haver espaço para a ambivalência que apro- 
xima pontos limítrofes como morte e vida, baixo e alto, medo e liberdade, evidenciando-se a consciência de um período histórico de transformações e renovações sociais semelhantes àqueles vividos por François Rabelais e que foi objeto de análise deste teórico russo.

Neste sentido, há um especial destaque para Ualalapi, romance publicado em 1987 e ganhador do Grande Prêmio da Ficção Narrativa, em 1990, cujo eixo temático gira em torno de uma espécie de relato étnico-histórico que, de acordo com postulados pós-modernos, voltam a recuperar traços da história factual, apontando para outros discursos possíveis a seu respeito.

Esta obra tematiza o passado recente de Moçambique numa perspectiva que faz com que este texto também seja reformulado e questionado à luz do presente. Para tal, o autor revisita o final do século XIX, no qual desponta o retrato cruel de um Império em decadência e degradação, cuja figura principal é Ngungunhane. Personagem de origem nguni, seu nome significa "o que domina”, e que, por essa razão, invade e coloniza povos como os tsongas no sul de Moçambique, tornando-se, por onze anos, Imperador das terras de Gaza. O texto reencena, ainda, os confrontos com changanes, tchopes e com o exército português, até sua deposição e exílio em Portugal. Na descrição dos acontecimentos, $\mathrm{Ba} \mathrm{Ka}$ Khosa retoma todo um mundo de tradições e mitos, sendo os negros, nessa altura, os heróis nas guerras de ocupação e na resistência ao invasor durante o processo de colonização do espaço moçambicano.

Assim, trazendo mais uma vez à tona o fato de que um discurso é sempre passível de diversas interpretações, o texto se abre a uma série de desdobramentos e ambiguidades. A primeira delas reside em seu próprio título, visto que Ualalapi é um guerreiro nguni cuja função no romance é apenas matar Mafemane, filho de Muzila, o irmão que planeja roubar a primogenitura de Mudungazi, que, após ascender ao trono, será conhecido como Ngungunhane. Ualalapi hesita, entretanto, em cumprir a ordem do futuro hosi, mas o faz para, em seguida, abandonar a trama através de uma fuga inexplicável que resulta em morte - a sua, a de sua mulher e a de seu filho. Se os heróis que despontaram no pós-guerra faziam jus a uma memória de glórias, a de Ualalapi reduz-se à escapada desenfreada, ao choro, ao delírio e à morte, revelando, assim, o espaço de degradação e de desassossego que o herói romanesco passou a vivenciar na contemporaneidade que o romance como gênero literário enuncia. 
Semelhante destino tem Mputa, personagem que sucumbe diante do poder tirânico do Imperador após ser injustamente acusado de assediar Domia, a primeira das muitas mulheres de Ngungunhane. Esta, não obstante o poder e as riquezas do marido, deseja o corpo esguio e rijo do guerreiro tsonga que a repudia. Mputa, todavia, desafia o poder supremo ao ingerir e resistir incólume ao "mondzo", bebida venenosa que faz com que se revele a inocência que o imperador manda, todavia, aniquilar (p. 51).

Por isso, no que se refere à operatividade a que nos referimos anteriormente, temos, numa primeira leitura, alguma dúvida em classificar esta obra quanto ao gênero, visto que, estruturalmente o livro parece ser uma coletânea de contos, todos precedidos, aliás, de dedicatórias. Contudo, sua ordenação, num sequenciamento temporal, nos permite associá-lo às características romanescas, sobretudo pela presença de Ngungunhane, cuja ação, invocada direta ou indiretamente, faz com que as diferentes histórias isoladas atuem tanto independente quanto dependentemente.

Ainda no plano da representação, percebe-se que a enunciação é múltipla, uma vez que as histórias são transmitidas por um narrador onisciente que, a partir de certa altura, cede espaço a diversas outras vozes enunciadoras, nem sempre consoantes. Tal se dá porque um outro narrador homodiegético surge, manifestando-se oniscientemente, antecipando situações e apontando para os também diversos elementos insólitos que permeiam a narrativa.

Se, em primeira instância, trata-se de um relato "épico" que exalta a bravura guerreira dos africanos, a partir de um determinado trecho, o sentimento inicial de euforia cede lugar a momentos de dúvidas e de incerteza que se depreendem de determinados núcleos diegéticos. Nestes, a justiça cede lugar à insensatez e à opressão corroboradas por situações de medo, terror, barbárie, arbitrariedades e abusos de poder da parte deste último Imperador moçambicano, que acabam por revelar um relato de cunho antiépico que questiona o estatuto aplicado, na altura, a determinados "heróis" nacionais.

Assim, os traços da "discursividade épica" (Leite, 1995, p. 37) requisitada por $\mathrm{Ba} \mathrm{Ka}$ Khosa focalizam fatos históricos de Moçambique a partir de sua composição diversa, a que se acrescentam os séculos marcados pela dominação portuguesa contra a qual Ngungunhanhe se voltou. Ao nível enunciativo, tal construção é alcançada pela multiplicidade de relatos que delineiam progressivamente os passos da personagem, dando conta das muitas ações 
que culminaram em seu exílio. Se comparado à narrativa clássica, o plurilinguismo e a polifonia encetados pelo romance constroem progressivamente o discurso sobre a nação, em vez de apresentá-lo única e exclusivamente através da voz de um aedo onisciente que contempla gloriosamente o passado.

Esta perspectiva é similarmente percebida na ambiguidade de que se revestem as fontes históricas utilizadas acerca de Ngungunhane, as quais, num aproveitamento paratextual, comparecem, mais uma vez, pelo uso de epígrafes. Trata-se de quatro citações oficiais de autoria de Ayres D'Ornellas, historiador que integrou a caravela régia, e Dr. Liengme, pastor protestante que conviveu com Ngungunhane, que o caracterizam, tanto física quanto psicologicamente, a partir de pontos de vista diametralmente opostos. Ao longo do relato, deparamonos com outras fontes, cuja integração tem uma função precisa: a de dialogar e questionar criticamente as versões estabelecidas pela história colonial e oficial acerca de Ngungunhane (Leite, 1998, p. 84). De igual modo, esse exercício de poder é comentado por outros enunciadores, sempre com viés anti-heróico, de modo que o resultado dos primeiros cinco textos é o despotismo, a falsidade, a prepotência e a crueldade de um governante obcecado pelo poder e pela riqueza, similares a alguns, aliás, que governam determinados países...

Ainda com relação às epígrafes, há a presença de textos bíblicos que remetem, naturalmente, ao discurso cristão e não apenas à mundividência africana, mas que, em contrapartida, não deixam de prenunciar penitência, dor e castigo e, no caso do último capítulo, precedido de citação do Apocalipse, antecipa o discurso derradeiro do hosi.

É justamente neste fragmento, intitulado "O último discurso de Ngungunhane", que a personagem é "reabilitada" em função das previsões que faz ao vaticinar fatos, como a perpetuação e a intensificação da exploração dos africanos pelos brancos, a degradação das tradições locais, a miséria e a morte resultantes da guerra colonial, a Independência de Moçambique e os desmandos que resultarão na guerra civil. Assim, e do ponto de vista pragmático, a figura do Imperador é denegrida em função de um poder injusto que o transforma num déspota; porém, em contrapartida, é enaltecida pela atribuição de um estatuto autóctone de visionário da história e "profeta da ideologia anticolonial" (Laranjeira, p. 326).

Outras ambigüidades se revelam também quando atentamos para linguagem, dada a heterogeneidade discursiva que faz com que vários registros, 
como os já citados trechos de documentos oficiais, textos bíblicos, comentários dos narradores acerca dos acontecimentos sobre Ngungunhane sejam mesclados num só texto. Essa multiplicidade discursiva deixa transparecer a convivência entre a tradição escrita e a oralidade africana, numa mescla que resulta num certo estranhamento ao convocar ao mesmo texto dados históricos e situações inverossímeis ao olhar ocidental, como os humores corporais excessivos, que pertencem à mundividência africana, assim como fenômenos escatológicos que a exacerbam. Tal lógica aponta para um posicionamento ideológico de seus enunciadores, fazendo surgir um realismo fantástico que, subvertendo os cânones estabelecidos para o gênero narrativo clássico, dota Ualalapi de uma linguagem aforística, grandiloqüente e hiperbólica, feita através de frases e períodos bastante longos, com adjetivação igualmente excessiva que confirmam o caráter mítico da linguagem etno-histórica.

Em termos mais concretos, estamos perante um discurso que se apropria de uma visão transcendental e simbólica da cultura tradicional, distanciando-se do prisma racionalista e científico do pensamento europeu. Nesta seqüência de idéias, será pertinente indagar se a tentativa de construção de uma ordem nova, fundamentada em concepções mítico-mágicas do universo, não será considerada inadequada por parte dos seus potenciais leitores, educados, na sua grande maioria, segundo modelos racionalistas ocidentais? (Matusse, p. 199).

Aproximando-nos do fim desta breve apresentação da obra de Ungulani $\mathrm{Ba} \mathrm{Ka}$ Khosa, chegamos às Histórias de amor e espanto, texto publicado em 1999, que é composto, todavia, de escritos nos anos 80. Os quatro contos "Dirce", "Confissão", "Construção" e "Uma pequena história" - remetem, como aponta Marcelo Panguana, em seu prefácio -, "a um tempo que já não é este tempo e que parece cada vez mais adormecido na memória coletiva", cujos acontecimentos "só se podem compreender à luz do passado" e que testemunham, segundo o autor, os anos de juventude em que foi professor nos campos de reeducação. O texto é, na verdade, a reunião de papéis que o autor descobriu perdidos e que, contrariando seus hábitos, resolveu reler, revivendo, desse modo, tempos "de esperança e de desilusão" (p. 45). Em um pequeno posfácio intitulado "Em jeito de qualquer coisa" e assinando apenas Ungulani, o autor afirma que a leitura trouxe-lhe à memória a imagem de personagens de seu passado, algumas delas já esquecidas, a que, todavia, somouse a visão de seus filhos. Foi exatamente esta simbiose que fez com que os 
contos fossem publicados, sobretudo porque, segundo Khosa, "o amor e o espanto ainda continuam" (p. 46).

Por fim, temos notícia da publicação, em 2005, de Os Sobreviventes da noite, que recebeu, em 2007, o Prêmio Literário José Craveirinha. Contudo, devido ao fato de a tiragem restringir-se apenas a Moçambique, este texto ainda não chegou até nós.

Assim, em última instância, vemos que, "escovando a história a contrapelo", a obra literária de Ungulani Ba Ka Khosa: Orgia de loucos, Ualalapi, Histórias de amor e espanto e No Reino dos abutres contempla a contemporaneidade de Moçambique, sem deixar, contudo, de questionar tanto o seu lugar na história, quanto sua função e seus incontáveis pontos de vista. Por isso, o discurso literário abre margens ao multiperspectivismo em que tanto o historiador quanto o romancista ampliam os limites entre sociedade e arte, desestabilizando as fronteiras da verdade, do presente e do passado, para fazer da interrogação do outrora uma nova categoria epistemológica.

Por esta razão, os textos de $\mathrm{Ba} \mathrm{Ka}$ Khosa consideram o passado como a "pré-história" do presente, atuando como mediadores entre o ontem e o hoje e, sobretudo, reunindo maneiras distintas de compreensão do atual contexto histórico moçambicano que, sem um pensamento crítico eficaz, estaria, invariavelmente, distanciado de suas raízes identitárias.

A autoconsciência que enunciam se alia à perspectiva ideológica apontada por Fredric Jameson ao reconhecer na literatura a função instrumental de um dado objeto cultural dotado de um "poder simultaneamente utópico e de afirmação simbólica de uma forma de classe específica e histórica” (p. 301). É ela que faz da narrativa não apenas um instrumento ideológico, mas o próprio paradigma de ideologização dos discursos que conferem aos leitores a capacidade de adentrar cada um de seus universos.

Ao refletir sobre o presente e colocar o futuro prometido em tensão com o passado, encenam-se claramente as relações entre o narrado e o vivido, que podem transitar no tempo, desvinculadas, portanto, do "fardo da história". 


\section{Referência Bibliográfica}

CAHEN, Michael. "Une Afrique lusophone libérale? La fin des premières republiques". In: Lusotopie. Paris, Karthala, 1995.

CHABAL, Patrick. Vozes moçambicanas, literatura e nacionalidade. Lisboa, Vega, 1994.

HAMILTON, Russel. Literatura Africana, Literatura Necessária II, Edições 70, Lisboa, 1983.

BAKHTIN, Mikhail. A Cultura popular na idade média e no renascimento - o contexto de François Rabelais. São Paulo-Brasília, EdUNB/Hucitec, 1996.

KHOSA, Ungulani Ba Ka. Histórias de amor e espanto. Maputo: Instituto Nacional do Livro e do Disco, 1999. - No reino dos abutres. Maputo: Imprensa Universitária, 2002. - Orgia de loucos. Maputo: Imprensa Nacional de Moçambique, 1990. . Ualalapi. Lisboa, Caminho,1991.

JAMESON, Fredric. O Inconsciente político: a narrativa como ato socialmente simbólico. São Paulo, Ática, 1992.

LARANJEIRA, Pires. Literaturas Africanas de Expressão Portuguesa: Lisboa, Universidade Aberta, 1995.

LEITE, Ana Mafalda. A Modalização épica nas literaturas africanas. Lisboa, Veja, 1995. " "Ualalapi, Ungulani Ba Ka Kosa" In: Oralidades e escritas nas literaturas africanas, Lisboa, Colibri, 1998.

MATUSSE, Gilberto.”O Modelo da narrativa fantástica hispano-americana e a construção da imagem de moçambicanidade em Ungulani Ba Ka Khosa”. In: CRISTÓVÃO, Fernando; FERRAZ, Maria de Lourdes e CARVALHO, Alberto (coord.). Nacionalismo e regionalismo nas literaturas lusófonas. Lisboa, Cosmos, 1997.

MEDINA, Cremilda de Araújo. Sonha mamana África. São Paulo, Edições Epopéia, 1987.

PÉLISSIER, René. Naissance du Mozambique: résistance et révoltes coloniales. Éditions Pélissier, França, 1984.

WHITE, Hayden. The content of the form - narrative discourse and historical representation. Baltimore/London: The John Hopkins University Press, 1992. . Trópicos do discurso - ensaios sobre a crítica da cultura. São Paulo, EdUSP, 2001. 